\title{
El cercado de la llama libre: transformaciones en el territorio comunitario de Curahuara de Carangas (prov. Sajama, dpto. Oruro, Bolivia 2007-2013)
}

\section{Carla Virginia Rodas Arano}

\section{(2) OpenEdition Journals \\ Edición electrónica \\ URL: http://journals.openedition.org/bifea/5289 \\ DOI: $10.4000 /$ bifea.5289 \\ ISSN: 2076-5827 \\ Editor \\ Institut Français d'Études Andines}

Edición impresa

Fecha de publicación: 1 agosto 2014

Paginación: 355-367

ISSN: 0303-7495

\section{Referencia electrónica}

Carla Virginia Rodas Arano, «El cercado de la llama libre: transformaciones en el territorio comunitario de Curahuara de Carangas (prov. Sajama, dpto. Oruro, Bolivia 2007-2013)», Bulletin de l'Institut français d'études andines [En línea], 43 (2) | 2014, Publicado el 08 agosto 2014, consultado el 06 noviembre 2020. URL : http://journals.openedition.org/bifea/5289; DOI : https://doi.org/10.4000/bifea.5289

\section{(c)}

Les contenus du Bulletin de l'Institut français d'études andines sont mis à disposition selon les termes de la licence Creative Commons Attribution - Pas d'Utilisation Commerciale - Pas de Modification 4.0 International. 
AvanCES DE
INVESTIGACIÓN 



\section{El cercado de la Ilama libre: transformaciones en el territorio comunitario de Curahuara de Carangas (prov. Sajama, dpto. Oruro, Bolivia 2007-2013)*}

Carla Virginia Rodas Arano**

\section{INTRODUCCIÓN}

La siguiente investigación se realiza en la marka ${ }^{1}$ aymara de Curahuara de Carangas, situada al sur de los Andes bolivianos (departamento de Oruro). En esta área se cría una inmensa cantidad de ganado camélido: desde las altas montañas hasta los pequeños valles. Por este motivo se le declaró como «Capital Boliviana de la Ganadería Camélida Sudamericana», de acuerdo a la ley n. ${ }^{\circ} 3157$ del 27 de agosto de $2005^{2}$.

Es así que la llama y la alpaca son seres significativos para la población curahuareña: estas intervienen no solo en el ámbito económico, sino en una serie de actividades rituales y cotidianas. Más aún, se relacionan con la continua movilidad espacial de

* Este artículo está basado en la investigación de maestría de Carla Rodas De la llama libre a la Ilama cercada: Cambios en la construcción territorial de Curahuara de Carangas (Prov. Sajama, Dpto. Oruro, Bolivia 2007-2013) (2013) para la Facultad Latinoamericana de Ciencias Sociales (FlacsoEcuador).

** Magíster en Estudios Socioambientales y Licenciada en Antropología. E-mail: caliope001@gmail.com

1 La marka es la «unidad territorial intermedia entre una provincia o 〈señorío» y los ayllus» (Medinacelli, 2012: 29). De esta manera, contiene dentro de sí varios ayllus.

2 Título compartido con el municipio de Turco. 
los curahuareños desde épocas preincaicas (hacia Chile). De este modo, así como la llama se mueve libre en el entorno3, los curahuareños pueden desplazarse por varios lugares sin desarraigarse de la marka (del grupo y del territorio).

También, las llamas y las alpacas influyen en la organización territorial curahuareña, debido a que el territorio está construido en base a los movimientos de la población. Esta circunstancia conlleva a la producción de un territorio disperso y extenso (territorio-red) que suele construirse y reconstruirse sin fragmentarse (territorio flexible). Asimismo, fortalece la organización territorial comunitaria, dado que siempre estuvo implicada con las tierras de uso común en los ayllus

En la actualidad (2013) la relación del curahuareño y el ganado camélido (y todo lo que incluye) corre el riesgo de cerrarse al plano económico, debido a la ejecución de proyectos de «desarrollo humano sostenible» que buscan mejorar la producción de las llamas y alpacas. Estas estrategias de desarrollo ganaderas se originaron en el año 2007, junto con la elaboración del Plan de desarrollo municipal originario, y se acrecentaron en el año 2011. Entre las actividades que hoy en día se están ejecutando, se encuentra el cerco del ganado camélido: práctica que acentuó los conflictos territoriales entre las tierras familiares (el cerco intensivo de sayañas 5 familiares que tiende a convertir las tierras comunitarias en tierras casi individuales).

Por este motivo, el presente estudio reflexiona acerca de esta problemática y cómo este cambio de relación entre el curahuareño y el camélido ha afectado a la comprensión del territorio. Es así que el tema de estudio fue planteado de la siguiente manera: la percepción del territorio de la marka aymara de Curahuara de Carangas (provincia Sajama, departamento de Oruro, Bolivia) a partir del año 2007. Es a partir de esta temática que surgió una interrogativa primordial: ¿Cómo se reconstruye el territorio de la marka aymara de Curahuara de Carangas a partir del cercado de los camélidos y de las sayañas familiares?

Esta problemática se abordó a través de un análisis cualitativo de los datos recopilados en el trabajo de campo. Por ende, se utilizó el método de la teoría fundamentada desde una perspectiva interpretativa. La interpretación de los datos

3 La llama libre es un término utilizado en Curahuara de Carangas y en este artículo hace referencia al antiguo modo de criar a la llama, sin cerco (lo cual no implica que la llama sea cimarrón). En Curahuara de Carangas se comprende que el cerco quita cierta libertad a la llama: «la parte negativa sería que el animal se siente muy cerrado, no está en esa libertad de expandirse, se ve limitado en su actividad, es como si estuviera en una carcelera. Pero, con patio grande» (D 45, 2013, entrevista). Y este es un pensamiento relacionado con la percepción curahuareña de la llama como persona: «Llama como persona, por ejemplo, la llama lo toman no tanto como hace la ciencia, lo toma como si fuera humano y le da todas las condiciones que tiene que tener. No hay tanto maltrato, no hay lo que es la investigación» (D 45, 2013, entrevista).

4 El ayllu es aquella «[u]nidad territorial, social, de parentesco y de identidad, núcleo de la organización socio étnico cultural andina» (Ayllu Sartañani, 1995: 459) que se cimenta principalmente en la familia: «[e]l ayllu equivale a familia (ali) es hasta hoy la unidad con la que se conforma nuestro tejido de organización social y político» (Thoa, 1995: 11).

5 La sayaña es una denominación aymara que traducida significa parcela y en Curahuara está relacionada con la tierra de uso familiar. 
se llevó a cabo a partir de tres pasos fundamentales (triangulación) de ida y vuelta: 1) la recolección de datos; 2) la redacción y sistematización de los datos; y, 3) el análisis y la revisión de la información para llenar vacíos en la investigación.

\section{RESUMEN DE LOS RESULTADOS DE LA INVESTIGACIÓN}

El territorio de Curahuara de Carangas puede ser entendido a partir de dos divisiones territoriales: la división político-administrativa y la división territorial aymara. Ambas organizaciones territoriales, actualmente, conviven una encima de la otra, de manera que se confunden en un tejido único denominado Curahuara de Carangas.

Curahuara de Carangas, como división político-administrativa, es un municipio 6 que se encuentra dentro de la provincia Sajama, al noroeste del departamento de Oruro, Bolivia. Y como división territorial aymara, es una marka de la unidad étnica mayor karankas

Esta marka se divide en siete ayllus de la parcialidad Aransaya ${ }^{8}$ y siete ayllus de la parcialidad Urinsaya9. En Aransaya se encuentran los ayllus de Jila Uta Qollana, Taypi Uta Qollana, Taypi Qollana, Sullka Uta Salla Qollana, Sullka Tunka, Jila Taypi Uta Qollana y Junta de Vecinos de Curahuara; y en Urinsaya se ubican los ayllus de Jila Uta Manasaya, Sullka Uta Manasaya, Jila Uta Choquemarka, Taypi Uta Choquemarka, Sullka Uta Choquemarka, Suni Uta Choquemarka y Suni Papel Pampa Choquemarka.

\section{1. La importancia de los movimientos espaciales en la construcción territorial curahuareña}

Los movimientos de los Carangas hacia la costa del Pacífico tiene una larga data: [C]onstituye la sección oeste de Carangas una zona de mucha importancia para el paso del Altiplano a la costa del Pacífico, los lazos de complementariedad unían a los Carangas con las vertientes del Pacífico probablemente desde tiempos antiguos (Michel, 2000: 60).

6 El municipio de Curahuara de Carangas figura como la primera sección de la provincia Sajama y se divide en cuatro cantones: Curahuara de Carangas, Sajama, Lagunas y Caripe. Este, a su vez, se divide en dos distritos municipales: distrito administrativo A (conformado por el cantón de Curahuara de Carangas) y distrito administrativo B (formado por los municipios de Sajama, Lagunas y Caripe).

7 Unidad étnica mayor karankas es el término utilizado por la agrupación Ayllu Sartañani (1995) para nombrar la extensión territorial mayor formada por 12 markas. Esta unidad étnica también es denominada como suyu Jach'a Carangas (Cottyn, 2012) o señorío Carangas (Medinacelli, 2012).

8 Según el Ayllu Sartañani, Aransaya es la «[m]itad o parcialidad de arriba de una marka» (Ayllu Sartañani, 1995: 468).

9 De acuerdo al Ayllu Sartañani, Urinsaya es la «[m]itad o parcialidad de debajo de una marka» (Ayllu Sartañani, 1995: 479). 
Para el periodo inka (1450-1530) los movimientos de los Carangas se extienden hacia los valles orientales:

La extensión del movimiento caravanero de los Carangas hacia los valles orientales parece haber sido promovida por la incursión inka, ya que ellos establecieron colonias de mitmas10 Carangas en los valles de Cochabamba y Chuquisaca (Lima, 2012: 57).

La influencia de estos movimientos en el territorio se vio reflejada en la creación de «archipiélagos multiétnicos», término utilizado por Rivière (1982) para nombrar los poblados conformados por personas de diferente origen. Estos «archipiélagos multiétnicos», de acuerdo a los datos11 analizados por Rivière (1982), se encontraban en los valles del mar como Codpa, Esquiña, Belén, Pachica y Tignamar. Siguiendo a este autor, en el caso de la movilización de los Carangas a los valles orientales de Cochabamba, Sucre y Tarija, la apropiación territorial se dio a partir de los mitimaes ${ }^{12}$.

Por lo tanto, en la época precolonial, los pobladores de este territorio se caracterizaron por sus constantes movimientos hacia otros lugares. Y, tal como indicaba la arqueóloga P. Lima, este movimiento se relacionaba con su principal modo de subsistencia, el ganado camélido:

[L]a principal característica de los Carangas era su movilidad, Ilegando hasta los valles de Azapa, Lluta, Codpa y Timar, en la costa del Pacífico donde se cultivaba maíz y coca, y a los valles de Tinkipaya en Cochabamba, Pojpo en Chuquisaca, además de los de Tarija y Arequipa. Este carácter de movilidad se debía a que eran una cultura llamera, característica mantenida hasta la actualidad (Lima, 2012: 57).

Este movimiento espacial en los Andes centro-sur (hacia la costa del Pacífico junto a camélidos en épocas precoloniales) fue analizado por Núñez \& Dillehay (1995), quienes denominaban a este tipo de movimientos - a diversos entornos - como «movilidad giratoria». Esta intensa movilidad espacial desdeépocas preincas ocasionó la construcción de un territorio disperso, que es descrito por Medinacelli (2010) dentro del territorio carangas durante el siglo XVI (comprendido a partir de la organización de estancias ${ }^{13}$ y comunidades en la época colonial —aunque este modo de ordenarse territorialmente se haya dado antes de la Colonia-):

10 Rivière (1982) señala que los mitimaes eran personas enviadas a lugares diferentes al de su origen. Siguiendo al autor, esta práctica era realizada con fines económicos y militares.

11 Datos obtenidos a partir de documentos del siglo XVII que denotan la presencia carangas en las costas del Pacífico. De acuerdo con Rivière (1982), los carangas fueron desprovistos de estos archipiélagos costeros en el siglo XVI.

12 Según Rivière (1982), los mitimaes eran personas enviadas a distintos lugares por motivos militares o económicos en tiempos antiguos. Por tal motivo, estos cobran importancia en el momento de la expansión inka.

13 La estancia, según Medinacelli es «como una unidad básica de organización territorial y social; estaba habitada por un grupo emparentado entre sí y ubicado en los lugares económica y simbólicamente importantes» (Medinacelli, 2010: 117). 
[S]eguramente sus tierras de pastoreo, y a veces también de agricultura, se encontraban dispersas por el territorio de su ayllu según la forma que conocemos donde cada comunario tenía su sayaña que constaba de un número variable de callpas ${ }^{14}$ o terrenos dispersos en distintos microclimas de la comunidad (Medinacelli, 1986: s. p. citado en Medinacelli, 2010: 118).

Esta organización dispersa del territorio aún es utilizada en Curahuara de Carangas dentro de los ayllus. Cada uno se divide en zonas dispersas dentro del municipio con diferentes microclimas (que se vincula con el cambio de pastos del ganado camélido en épocas pasadas). Incluso, a estas zonas se suman los lugares fuera del municipio donde viven los miembros del ayllu15, dando lugar a un territorio extendido.

De esta manera, actualmente el territorio de Curahuara de Carangas es entendido como un territorio-red, que contiene tanto el territorio disperso como el territorio extendido:

[A]quí, las redes sociales funcionaban como un organizador del grupo, conectando todos los elementos de la comunidad-territorio: las personas ubicadas en el sitio de origen y los residentes en otras localidades; y los lugares próximos y los sitios distantes (Rodas, 2011: 87).

Así, ahora no es extraordinario encontrar a curahuareños (generalmente jóvenes, entre los quince y veinticinco años de edad) trabajando durante las vacaciones o viviendo de forma intermitente en los valles de Chile. De la misma manera, no es raro hallar a chilenos (parejas de los curahuareños que viven en Chile o hijos e hijas que nacieron en este país) en las fiestas de Curahuara de Carangas.

Por tal motivo, la actual configuración territorial de la marka carangas, en ciertas ocasiones sobrepasa las fronteras político-administrativas (debido a las prácticas realizadas por los curahuareños desde épocas preincas). De forma que la movilidad espacial Ilega a integrarse a la cultura curahuareña, la cual podría denominarse «cultura de la movilidad» — término utilizado por De la Torre Ávila (2006) para indicar el modo de vida de los migrantes del valle alto cochabambino-.

Es así que algunos hijos e hijas de residentes 16 curahuareños —nacidos en el extranjero- consideran que Curahuara se construye más allá de las fronteras:

${ }^{14}$ La callpa es una denominación aymara que significa barbecho, y de acuerdo a Medinacelli (2010), hace referencia a las tierras de la comunidad que se esparcían en diferentes climas.

15 En cada familia curahuareña existen personas que se han asentado fuera del municipio: en Bolivia los curahuareños se encuentran mayormente en La Paz y Cochabamba, y en menor proporción en Oruro, Los Yungas, Alto Beni, Cochabamba y Santa Cruz; fuera de Bolivia se hallan en Chile (donde principalmente se asientan), Perú, Argentina, Brasil, España e Italia.

16 En esta investigación se comprende la palabra residente a partir de las interpretaciones de los curahuareños. Así, los curahuareños utilizan esta palabra cotidianamente para denominar a los miembros de la marka y del ayllu que residen en otros países, otros departamentos, otros municipios y otras ciudades (fuera del municipio de Curahuara de Carangas). 
El aymara es un pueblo sin fronteras, no discriminemos a los chilenos, a los argentinos, que los peruanos, que los ecuatorianos, sino todos somos aymara $(X \sim 35,2013 \text {, entrevista) })^{17}$.

\section{2. Los camélidos y el territorio comunitario}

Lograr mantener este territorio-red, que traspasa linderos y que se reelabora por la movilidad espacial, es un trabajo arduo que implica realizar ciertas prácticas que vinculan el lugar de origen con los lugares distantes. De modo que para conservar este territorio flexible se realizan una serie de prácticas cohesionadoras comunitarias: se pasan cargos de autoridad, se asisten a las festividades, se identifican con el equipo de fútbol de su ayllu (a la vez que colaboran con este) y se realizan actividades respecto a la crianza de las llamas y alpacas.

De estas actividades, es la última (la crianza de llamas y alpacas) la que se relaciona íntimamente con la construcción de un territorio abierto, que puede modificarse por la movilidad espacial de la población.

Las agrupaciones pastoriles, a lo largo de la historia, se han distinguido por su intensa movilidad espacial. Es así que se les caracteriza frecuentemente como nómadas (Barth, 1961), seminómadas, semisedentarias o trashumantes (Khazanov, 1994). En el caso de las agrupaciones andinas es muy probable que los movimientos hacia la costa del Pacífico hayan sido realizados al seguir a los camélidos:

No se debe rechazar la idea de que los cazadores andinos fueron posiblemente los primeros en adoptar sus hábitos al comportamiento de los camélidos salvajes (Núñez \& Dillehay, 1995: 26).

La relación sostenida entre los camélidos y los antiguos habitantes no ha cambiado demasiado: las llamas aún son percibidas como compañeras autónomas, aunque en la actualidad las personas curahuareñas no realizan enormes trayectos de un lugar a otro junto a estos camélidos. Es así que se concibe a la llama como un ser diferente a los demás animales y más parecido a una persona18:

Lo trata como a un ser humano más, lo que le falta a ese animal simplemente sería hablar (D 45, 2013, entrevista).

Por este motivo la crianza de la llama está asociada al cuidado de un pariente:

[Y] lo ve al animal, en este caso la llama, como una persona. Y como una persona viene a ser parte de su familia (D 45, 2013, entrevista).

17 Entrevista abierta realizada al hijo de un residente curahuareño nacido en Chile (conversación llevada a cabo en la festividad de carnavales).

18 La llama en Curahuara de Carangas es considerada diferente de los demás animales, y esto debido a su particular personalidad: «Los hábitos que tiene la llama es especial, no es como el ovino, ¿no?, que el pastito lo arranca desde abajo, entonces sabe en qué momento tiene que comer, en qué momento tiene que guardar, ya, y ya hace un equilibrio entre el medio ambiente, ya, incluso sus hábitos de alimentación y de bebidas son mucho más estrictas» (D 45, 2013, entrevista). 
Las investigación de Haber en Argentina muestra la misma relación de cariño entre el cuidador o cuidadora y los camélidos durante la festividad de los animales:

[L]a persona particular a cargo del cuidado de los animales es honrada en su relación a ellos, y es reconocida como la criadora o amparadora, es decir, la persona que los cuida, ama y posee (Haber, 2010: 82).

Asimismo, las investigaciones de Dransart (1999; 2002) en Chile, contrarias a las posiciones de domesticación de animales a partir de una relación desigual19, señalan que la domesticación de los camélidos en los Andes no es un proceso de cercado o violencia, sino de socialización:

Los animales domesticados, en este caso los camélidos, realizan la condición de llamahood20 o alpacahood21 durante su propio ciclo vital. Esta realización tiene su paralelos en el proceso de socialización de los humanos (Dransart, 1999: 126).

De esta manera, la conducta autonómica del camélido es apreciada por los curahuareños, al punto que perciben a la llama y a la alpaca con cuatro particularidades22: 1) el camélido como persona; 2) el camélido como parte de la familia; 3) el camélido como regalo sagrado; y, 4) el camélido como parte del todo. En todo caso, la relación entre el curahuareño y el camélido parece ser de tipo horizontal (más que de dominio — vertical—), similar a la relación de confianza descrita por Ingold (2000) para los cazadores. Es en este punto donde la relación entre el ser humano y el camélido se refleja en la producción territorial curahuareña: el manejo horizontal del territorio.

El manejo horizontal del territorio no es nada más que el territorio disperso, que ya se había explicado exhaustivamente. Además, a esta organización territorial dispersa se suma el territorio extendido, el cual se asemeja a la relación del camélido, el ser humano y la movilidad. De esta manera el territorio-red de la marka de Curahuara de Carangas es reflejo de la relación de los curahuareños con las llamas y las alpacas.

Las formas de crianza del camélido comprenden los movimientos del ganado para la renovación de pastos, actividad que se fue reduciendo a áreas cada vez más pequeñas con el pasar de los años (especialmente hace más de un quinquenio atrás). Si bien al inicio la renovación de pastos comprendía el tránsito hacia las costas de Chile, posteriormente comprendió las diferentes

${ }^{19}$ Como la propuesta de Ingold, quien consideró que la domesticación en sociedades pastoriles gira en torno a la dominación: «[S]ostengo que relaciones entre cazadores y presas se basan en un principio de confianza, constituidas por una combinación de autonomía y dependencia. La relación hombre-animal en pastoreo, por el contrario, se basa en un principio de dominación» (Ingold, 2000: 10).

20 Término en inglés para denominar la personalidad de la llama.

21 Término en inglés para denominar la personalidad de la alpaca.

22 Para este análisis se utilizaron las ideas planteadas por D 45, quien diferenció los métodos de crianza de camélidos occidentales y andinos. Es así que surgieron estas cuatro particularidades, las cuales relacionó con el método andino de crianza del camélido. 
zonas de un ayllu. En la actualidad, esta renovación de pastos se ha reducido a desplazar el ganado camélido entre las diferentes sayañas familiares (si la familia tiene más de una — mayormente ubicadas en una sola zona por normativa del ayllu -) de las tierras más altas hacia las tierras más bajas, o a mover a las llamas y a las alpacas dentro de una sola sayaña familiar (con los nuevos métodos implementados de cercos).

Así, el territorio de la familia en el ayllu comprende diversos lugares con distintas características para la crianza del ganado camélido. Este manejo territorial a través del movimiento beneficia tanto al camélido (para su alimentación) como al curahuareño (que no desperdicia nada). Este modo de apropiación territorial (por medio de la movilidad espacial) de las familias en el ayllu es repetido a nivel de la marka (con el movimiento de los residentes a otros lugares).

Aquí es trascendental reflexionar, que a partir del manejo territorial mediante el movimiento, existían lugares de uso común dentro del ayllu. De esta forma, en épocas antiguas el ayllu andino estaba conformado por tierras de uso familiar (sayañas) y tierras de uso común donde las llamas y las alpacas podían pastar. Este modo de manejo territorial fue analizado por Yampara en Chambi Grande23, quien describió la organización territorial del ayllu en base a la presencia de tierras de uso familiar (sayaña) y tierras de uso común para el pastoreo del ganado (saraqa)24:

Mientras que la «saraqa〉 es el espacio territorial de circulación comunitaria, compartido por varias familias, allí funcionan las «aynuqa y las anaqa`25, su uso está guiado por los Prognosis climáticos anuales de los samawt'a/ Ilapaku〉26, regulados y asignados por los 〈qamana 27 del Ayllu, alternando entre spuruma y qallpas (en descanso y uso) (Yampara, 2001: 93).

Asimismo, además de ser tierras de uso común para el pastoreo, estas saraqas estaban relacionadas con tierras ubicadas en diferentes microclimas. En este punto la organización territorial incluía lugares lejanos, de manera que se daba el manejo territorial extendido:

23 Chambi Grande es un ayllu que se encuentra en la provincia Gualberto Villarroel, departamento de La Paz, Bolivia. Este ayllu se encuentra cerca de la frontera con el departamento de Oruro y colinda con el Jach'a Carangas.

24 El término saraqa actualmente no es utilizado por los curahuareños, no obstante las curahuareñas y los curahuareños indicaron que en el tiempo de sus abuelos existían tierras de uso común para el pastoreo (no recuerdan su denominación) y posiblemente estaban relacionados con los bofedales (lugares donde hay fuentes de agua): «[N]ormalmente, antiguamente, antes todos tenía derecho al agua. Digamos acá había un vecino, dos vecinos, tres vecinos, cuatro, cinco, seis, siete, entonces como este era la vertiente todos los animales iban a beber cada uno. ¿Pero qué ocurre?, resultado que hay gente inescrupulosa que lo toma el cercado de ahí y le estamos quitando el agua» (D 45 , 2013, entrevista).

25 Las aynuqa, según Yampara (2001), son lugares donde trabajan todas las familias del ayllu en actividades agrícolas. Las anaqa son sitios utilizados generalmente para el pastoreo de ganado.

26 El amawt'a, según Yampara (2001), es la persona más sabia del grupo. El llapaku es la persona dedicada a pronosticar los cambios en el entorno para el año agrícola.

27 Los qamana son las autoridades del ayllu que se dedican a la producción. 
[L]a 〈saraqa` extendida (territorialidad discontinua y compartida) comprende los otros espacios ecológicos como las 〈saraqa〉 de la 〈qirwa〉 (tierras de los valles), las 〈saraqa〉 de 〈yunka〉 (tierras de los yungas), las 〈saraqa〉 de los 〈chumi〉 y las 〈saraqa〉 de 〈quta laka〉 (tierras de la costa del mar) (Yampara, 2001: 94).

En la actualidad se vienen dando transformaciones en Curahuara de Carangas tras el cambio en la relación del curahuareño con la llama. De tal modo, cambia el territorio de uso común utilizado para el pastoreo del ganado camélido. Estos cambios en las percepciones de los curahuareños se debieron a la introducción de un nuevo método de crianza de camélidos.

Este nuevo método de crianza del ganado camélido ingresó en la marka con la implementación del Plan maestro de camélidos (2007-2011) y se intensificó en el año 2011:

[E]so es muy recién, será unos tres años por mucho, más antes así no más pasaban en pampa comiendo (los camélidos), ahora ya tienen cercado (AV 50, 2013, entrevista).

De esta manera, estos métodos de crianza comenzaron a ejecutarse con el propósito de un supuesto «desarrollo humano sostenible».

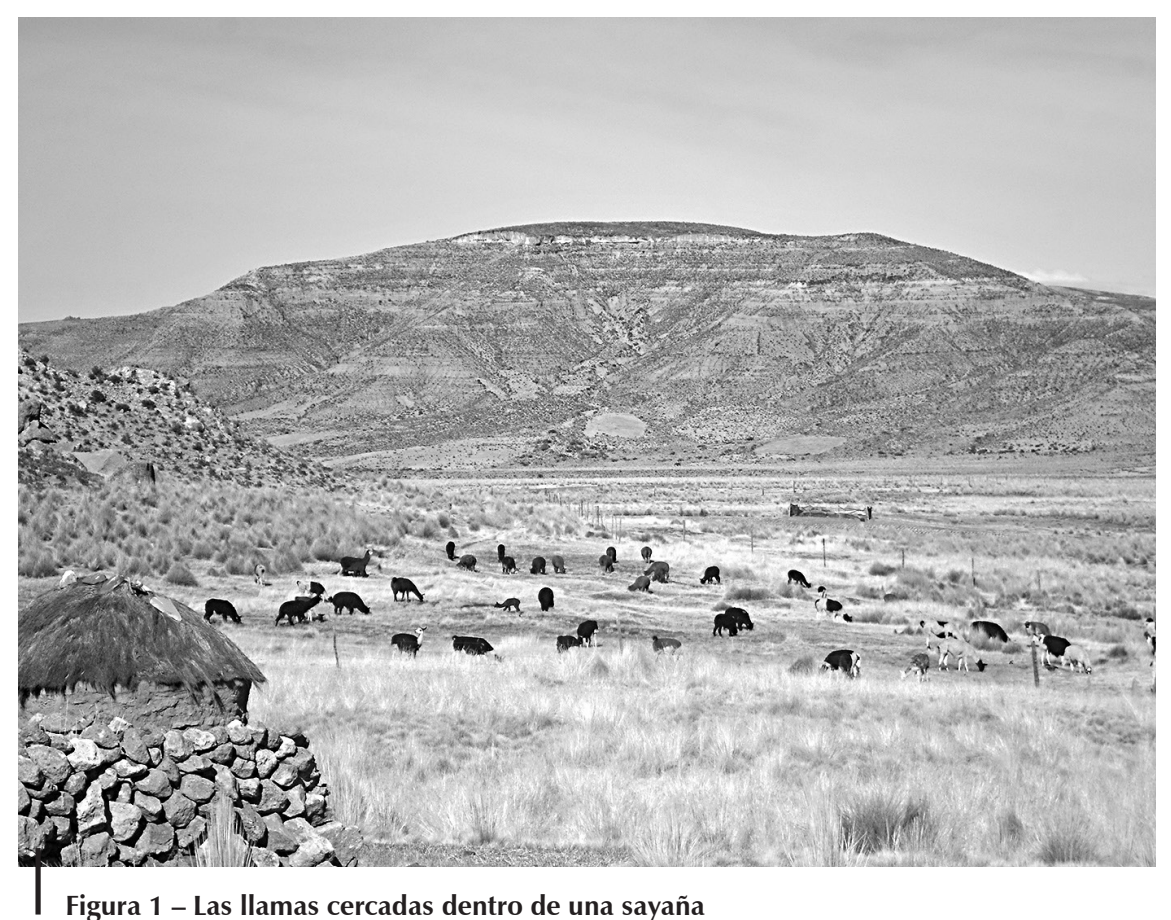

Figura 1 - Las Ilamas cercadas dentro de una sayaña

Fuente y elaboración: Carla Rodas, fotografía tomada el 22 de mayo de 2013. En Rodas (2013) 
Es a partir de la implementación de estos proyectos que las llamas y las alpacas ya no son vistas como personas, sino como meros productos. Así, la actitud frente a este animal ha comenzado a cambiar: si antes estaban pendientes del comportamiento de las llamas y las alpacas, ahora las dejan encerradas en los cercos para poder realizar otras actividades. De esta manera algunos curahuareños indican:

[T]odito los han abandonado (...) no hay nadie aquí, así los ganados botados, acá arriba, más allá, ya no hay gente, así abandonados, ganado hay, pero, ganado botado está (C79, 2013, entrevista).

Aquí es muy probable que por la «modernidad» y el «desarrollo» se explote al camélido sin importar la relación de compañerismo formada desde tiempos remotos:

Pero habría que subrayar que el modus operandi del capital moderno en su fase ecológica no es el beneficio como tal sino una dominación semiótica. Lo que importa es instituís socialmente la idea de que todo son bienes de consumo, de tal forma que se considere como capitales a toda la naturaleza (y la naturaleza humana), ipso facto al servicio del capitalismo como forma social legítima (O'Connor, 1994: 31).

Es en este momento cuando la relación de confianza cambia por una relación de dominio. Y, más aún, transforma las percepciones sobre el territorio en Curahuara de Carangas.

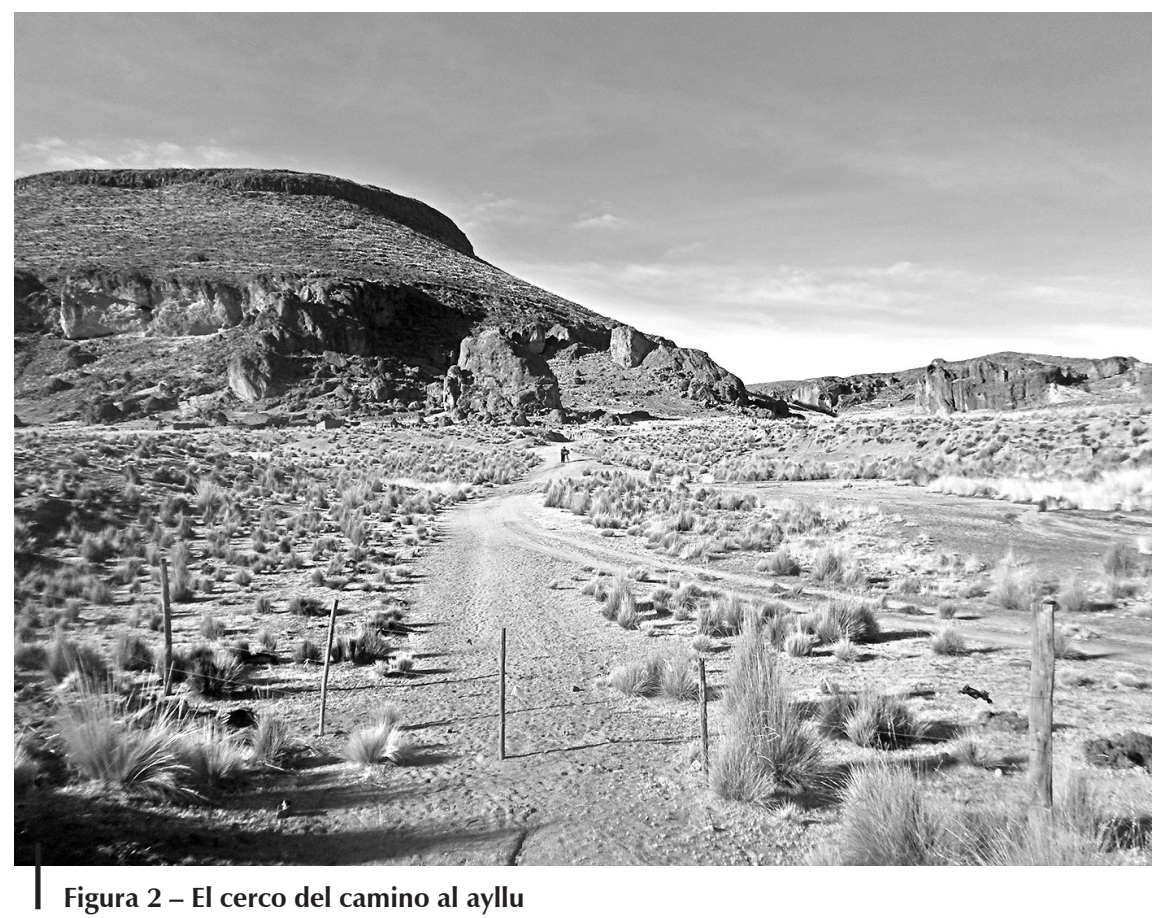

Fuente y elaboración: Carla Rodas, fotografía tomada el 22 de mayo de 2013. En Rodas (2013) 
Así, si bien el camélido estaba relacionado con las tierras de uso común (que de cierto modo mantenían la idea de un territorio comunitario), tras cambiar el vínculo con la llama y la alpaca (a una relación de producción) estas tierras van adquiriendo un carácter individual y casi privado que ocasiona mayores conflictos territoriales.

\section{CONCLUSIONES}

Este trabajo no intenta dar una solución a estos problemas sobre tierras, sino busca llevar a la reflexión a partir de la compresión del territorio. El análisis permite reflexionar acerca de la última construcción territorial curahuareña que se viene dando desde hace seis años (por la implementación de proyectos de cercos para el ganado camélido). Esta última producción territorial comprende cambios radicales respecto a la cultura y al modo de vida curahuareño. De esta manera, se producen una serie de transformaciones en la marka con el afán de lograr «modernidad», «desarrollo» o estar «mejor».

Estos cambios comenzaron a surgir a partir de la implementación de proyectos de «desarrollo humano sostenible» respecto a la crianza del ganado camélido. Es así que la ejecución de estos proyectos cambió las prácticas cotidianas realizadas en Curahuara de Carangas. Asimismo, y resulta ser la reforma más importante, se transformó la relación sostenida entre el curahuareño y el camélido: de un vínculo de compañerismo a un vínculo netamente económico.

Aquí, los cambios ocurridos en Curahuara de Carangas fueron dados en tres ámbitos: 1) la relación entre el curahuareño y el camélido; 2) la movilidad espacial de la población; y, 3) la percepción del territorio. Estos tres ámbitos están profundamente conectados, de manera que si existe alguna reforma en uno de ellos, por consiguiente, cambian los otros dos. De la misma manera, si existe cierto cambio en la familia curahuareña, por ende, se transforma el ayllu y la marka.

El ayllu estaba compuesto antiguamente por sayañas de uso familiar y tierras de uso común (donde pastoreaban las llamas y las alpacas). En cambio, la marka estaba conformada por lugares cercanos y por lugares lejanos (territorio-red): una organización territorial que en épocas precoloniales fue dispersa y en tiempos más recientes fue extensa. De esta forma, en ambos casos existieron transformaciones radicales tras la implementación de los cercos de las llamas y las alpacas.

Si bien los cercos estaban destinados a los camélidos, también fueron utilizados para rodear las sayañas familiares, de manera que se agravaron los conflictos entre vecinos del ayllu. Es así que el manejo territorial cambia, al igual que el modo de apropiación territorial (dado que anteriormente la movilidad espacial era una forma de apropiación territorial curahuareña).

Hoy en día es más difícil trasladarse de un lugar a otro junto con el ganado camélido ya que los cercos cortan el camino. Ya no se puede transitar libremente entre las sayañas del ayllu, lo que se hacía frecuentemente en épocas pasadas. Por ende, es probable que el manejo continuo y extendido del territorio se reduzca a áreas discontinuas que corren el peligro de desfragmentarse al no existir muchos 
desplazamientos. Asimismo, es probable que la flexibilidad que caracterizaba al territorio curahuareño (característica de las tierras comunitarias curahuareñas) vaya perdiéndose con los años y pase de un territorio abierto a un territorio cerrado por fronteras fijas (característica de las tierras individuales).

\section{Referencias citadas}

\section{Documentos}

Ley n. ${ }^{\circ} 3157,25$ de agosto del año 2005

\section{Entrevistas}

$\mathrm{AV} \sim 50,10$ de junio de 2013

C79, 23 de mayo de 2013

D 45, 10 de junio de 2013

X $\sim 35,13$ de febrero de 2013

\section{Publicaciones}

AYLLU SARTAÑANI, 1995 - Perspectivas de desentralización en Karankas: la visión comunitaria, 485 pp.; La Paz: Proade-Ildis.

BARTH, F., 1961 - Nomads of South Persia. The Basseri Tribe of the Khamseh Confederacy, 159 pp.; Oslo: Oslo University Press.

COTTYN, H., 2012 - ¿Ruptura sin reforma? El proceso de la Reforma Agraria en Turco. In: Turco marka. Hombres, dioses y paisaje en la historia de un pueblo orureño. Historiaarqueología-arquitectura (X. Medinacelli, ed.): 161-190; La Paz: IEB.

DRANSART, P., 1999 - La domesticación de los camélidos en los Andes centro-sur. Una reconsideración. Relaciones de la Sociedad Argentina de Antropología, n. ${ }^{\circ}$ 24: 125 138.

DRANSART, P., 2002 - Earth, water, fleece and fabric: an ethnography and archaeology of Andean camelid herding, 308 pp.; Londres: Routledge.

DE LA TORRE ÁVILA, L., 2006 - No llores, prenda, pronto volveré. Migración, movilidad social, herida familiar y desarrollo, 216 pp.; La Paz, Lima: Fundación PIEB, Instituto Francés de Estudios Andinos, Universidad Católica Boliviana «San Pablo».

HABER, A., 2010 - Animismo, relacionalidad, vida: perspectivas post-occidentales. In: Biografías de paisajes y seres: visiones desde la arqueología sudamericana (D. Hermo \& L. Miolli, eds.): 75-98; Córdoba: Encuentro Grupo Editor.

INGOLD, T., 2000 - The perception of the environment. Essays on livelihood, dwelling and skill, 465 pp.; London: Routdlege.

KHAZANOV, A., 1994 - Nomads and the outside world, 382 pp.; Wisconsin: University of Wisconsin Press.

LIMA, P., 2012 - Caranguillas: ¿la capital pre-inka de los Carangas? Re-estructuración de la perspectiva territorial a partir de la presencia de los Inkas. In: Turco marka. Hombres, dioses y paisaje en la historia de un pueblo orureño. Historia-arqueologíaarquitectura (X. Medinacelli, ed.): 49-73; La Paz: IEB. 
MEDINACELLI, X., 2010 - Sariri. Los llameros y la construcción de la sociedad colonial, 390 pp.; La Paz: Instituto Francés de Estudios Andinos, Plural Editores, ASDI, IEB.

MEDINACELLI, X., 2012 - Paisaje en movimiento. Turco y la erupción del Huayna Putina. In: Turco marka. Hombres, dioses y paisaje en la historia de un pueblo orureño. Historia-arqueología-arquitectura (X. Medinacelli, ed.): 21-47; La Paz: IEB.

MICHEL, M., 2000 - El señorío prehispánico de Carangas. Disertación para el diplomado superior en derechos de los pueblos indígenas; La Paz: Universidad de la Cordillera.

MUNICIPIO DE CURAHUARA DE CARANGAS, 2007 - Plan maestro de camélidos 20072011; Curahuara de Carangas: Consejo de Autoridades Originarias Curahuara Marca.

NÚÑEZ, L. \& DILLEHAY, T., 1995 - Movilidad giratoria, armonía social y desarrollo en los Andes Meridionales: Patrones de Tráfico e interacción económica, 190 pp.; Antofagasta: Universidad Católica del Norte.

O'CONNOR, M., 1994 - El mercadeo de la naturaleza. Sobre los infortunios de la naturaleza capitalista. Ecología política. Cuadernos de debate internacional, $\mathbf{n} .^{\circ} \mathbf{7}$ : 15-34.

RIVIÈRE, G., 1982 - Sabaya: Structures-économiques et représentations symboliques dans le Carangas-Bolivie. Disertación doctoral. Universidad de París.

RODAS, C., 2011 - «Siempre llevo mi tierra conmigo». Movilidad, territorialidad e identidad en el Municipio de Coroico (Dpto. La Paz, Bolivia 2007-2009). Disertación para licenciatura. Universidad Mayor de San Andrés.

RODAS, C., 2013 - De la llama libre a la llama cercada: Cambios en la construcción territorial de Curahuara de Carangas (Prov. Sajama, Dpto. Oruro, Bolivia 20072013). Disertación para maestría. Facultad Latinoamericana de Ciencias SocialesEcuador.

THOA, 1995 - El ayllu: pasado y futuro de los pueblos indígenas, 41 pp.; La Paz: Aruwiyiri.

YAMPARA, S., 2001 - El ayllu y la territorialidad en los andes. Una aproximación a Chambi Grande, 207 pp.; El Alto: Qamán Pacha Cada-Upea. 